\title{
“Tully", de Jason Reitman (1h 36 min, 2018)
}

\section{Giovana Acacia Tempesta e Juliana Kitayama Cabral}

\section{(2) OpenEdition}

Journals

Edição electrónica

URL: http://journals.openedition.org/aa/4319

DOI: $10.4000 /$ aa. 4319

ISSN: 2357-738X

\section{Editora}

Programa de Pós-Graduação em Antropologia Social (UnB)

\section{Edição impressa}

Data de publição: 1 dezembro 2019

Paginação: $355-360$

ISSN: 0102-4302

\section{Refêrencia eletrónica}

Giovana Acacia Tempesta e Juliana Kitayama Cabral, «"Tully", de Jason Reitman (1h 36 min, 2018)», Anuário Antropológico [Online], v.44 n.2 | 2019, posto online no dia 03 dezembro 2019, consultado o 28 abril 2021. URL: http://journals.openedition.org/aa/4319; DOI: https://doi.org/10.4000/aa.4319

\section{(c) (i) () $\Theta$}

Anuário Antropológico is licensed under a Creative Commons Atribuição-Uso Não-Comercial-Proibição de realização de Obras Derivadas 4.0 International. 


\title{
“Tully", de Jason Reitman (1h 36 min, 2018)
}

\author{
Giovana Acacia Tempesta - Brasil \\ Universidade de Brasília - Brasil
}

Juliana Kitayama Cabral

Universidade de Brasília - Brasil

\section{Atenção! Contém spoilers.}

Tully, filme dirigido por Jason Reitman, com roteiro de Diablo Cody (EUA, 2018), aborda as experiências de gestação, puerpério e maternidade de Marlo (Charlize Theron), uma mulher de 40 anos, branca, casada, de classe média, que vive nos arredores de Nova Iorque, Estados Unidos, já tem dois filhos e está na terceira gravidez. A narrativa se inicia algumas semanas antes do parto e focaliza as tensões em torno de uma experiência de puerpério desestabilizadora. Drew (Ron Livingston), o marido de Marlo, é um homem que trabalha bastante e gosta de jogar videogame nas horas vagas. Licenciada de seu trabalho na área de recursos humanos de uma fábrica de cereais (profissão que em nada se aproxima de sua formação em literatura), Marlo dedica toda a sua energia aos cuidados das crianças e da casa. A rede de apoio do casal se resume ao irmão de Marlo, Craig (Mark Duplass) e a esposa Elyse (Elaine Tan), que têm uma vida confortável e estável. É esse irmão que se oferece para contratar uma babá noturna para ajudar Marlo.

Em várias cenas, a protagonista deprecia a si mesma e dá sinais de tristeza, exaustão e distanciamento emocional; após o nascimento da terceira filha, ela compara seu corpo a um território devastado pela guerra. Marlo lida diariamente com a privação de sono, o choro estridente da recém-nascida, os desafios singulares envolvidos na criação do outro filho que apresenta comportamentos "peculiares", os julgamentos sociais sobre diversos aspectos de sua vida pessoal, dificuldades financeiras, a desordem na casa, a culpa por não corresponder aos padrões ideais de maternidade e dissabores no casamento. A exaustão a leva a superar a resistência demonstrada inicialmente, e ela acaba aceitando a sugestão do irmão; surge então a misteriosa figura de Tully (Mackenzie Davis), uma jovem esbelta e vibrante.

No decorrer do filme, Tully transforma a dinâmica da casa, torna a convivência familiar mais harmoniosa e se mostra uma grande companheira de Marlo. As duas têm várias características em comum, como o gosto musical e a bebida favorita. 
Tudo vai bem até que, uma noite, elas decidem sair para se divertir na cidade e não avisam Drew, que estava no quarto. Então vêm à tona a nostalgia que Marlo nutre pela sua juventude e o pesar pelas limitações enfrentadas na nova fase da vida, sentimentos que se misturam à sensação de pertencimento associada à família nuclear.

Tully anuncia abruptamente que não pode manter a relação e Marlo reage de modo negativo. Embriagadas e cansadas, elas voltam para casa de carro e acontece um acidente sério. Marlo perde o controle da direção ao passar por uma ponte e o carro cai dentro do rio; ela fica inconsciente e é salva por uma sereia. No hospital, seu marido demonstra surpresa e preocupação; ele diz à psiquiatra que a esposa parecia ótima e que ela nunca antes havia deixado os filhos em casa "sozinhos". A psiquiatra desconfia da avaliação do marido e ele então admite que Marlo sofrera bastante após o nascimento do segundo filho. Acamada, a protagonista recebe a visita de Tully e, nesse momento, podemos entender que a babá-confidente representa um aspecto da personalidade fragmentada da mulher puérpera, possivelmente um recurso interno acionado em um momento de sofrimento intenso, em meio ao cenário de sobrecarga física e mental e ausência de empatia e apoio efetivo. Ao final, Tully desaparece, Marlo se recupera do acidente e Drew se torna mais presente na vida doméstica.

O filme explicita uma realidade vivida por muitas mulheres, uma realidade sobre a qual pouco se fala e se estuda. No Brasil, o puerpério começou a ganhar relevância social no bojo do movimento pela humanização do parto e nascimento, nos anos 1980. No entanto, o tema ainda não se tornou objeto de interesse mais pronunciado na seara das Ciências Sociais, a despeito da ampla gama de questões culturais que abrange, tais como: técnicas corporais específicas envolvidas na amamentação, no sono e na forma de carregar o bebê; métodos de introdução alimentar; as relações conjugais; as novas expectativas de maternidade e paternidade; a situação da mulher mãe no mundo do trabalho; as relações de cuidado, que podem abranger creches, babás, vizinhança e família nuclear e extensa; a vontade de muitas mulheres de voltarem a ter a mesma forma corporal de antes da gestação; os casos de mães que não amam os filhos; as mães de bebês que nascem com doenças graves, crônicas e raras, bem como deficiências nem sempre facilmente diagnosticadas; as associações entre violência obstétrica e depressão pós-parto; a psiquiatrização e a prescrição de medicamentos, dentre outras.

Neste sentido, cabe perguntar: o que significa o puerpério para diferentes atores sociais (mulheres mães de diferentes segmentos socioeconômicos, cônjuges, profissionais de saúde, operadores do direito, doulas)? Quais os significados envolvidos nas principais categorias geralmente mobilizadas durante esse período, a saber, "res- 
guardo", depressão pós-parto, baby blues, solidão e psicose puerperal?

$\mathrm{Na}$ grande mídia brasileira, o tema do puerpério por vezes é tratado sob a ótica da patologização. Em uma matéria de 2018, uma revista de ampla circulação noticiou um medicamento para a depressão pós-parto que estava sendo testado na Europa e nos Estados Unidos. Baseando-se em entrevistas com médicos e focalizando o fenômeno como um transtorno de ordem individual, o texto informa que sete em cada dez mulheres brasileiras sofrem de algum tipo de tristeza após o parto ("Uma luz na escuridão", matéria assinada por Giulia Vidale, publicada na revista Veja, em 29 de agosto de 2018).

A experiência do puerpério vem sendo monopolizada pela linguagem biomédica, mas o isolamento social temporário vivido pela mulher após o parto, combinado aos múltiplos apelos para que ela aja como uma "mulher-maravilha", provavelmente são fatores que contribuem para a intensificação de sentimentos negativos e transtornos mais ou menos graves. Desse modo, podemos imaginar que a personagem Marlo poderia estar vivendo um estado liminar, nos termos formulados por Victor Turner (1974), para quem a "liminaridade" consiste em uma condição transitória e efêmera de um sujeito que se separa da estrutura social e ocupa um lugar indefinido até que se conclua o ritual, quando ele é alocado na posição apropriada.

Marlo parece estar atravessando solitariamente um rito de passagem, pois experimenta uma espécie de "morte social”, em que sua identidade parece cindida, algumas normas sociais (como a higiene pessoal e a alimentação) perdem a validade, ela se torna "invisível” e passa a se movimentar em um mundo "imaginário". Após o choque do acidente, ela consegue integrar todos esses aspectos e se descobre uma nova mulher mãe, reincorporando-se posteriormente ao status de mulher branca de classe média norte-americana.

Enquanto efeito de uma provável dissociação (fenômeno psicológico que diz respeito à desconexão entre pensamentos, emoções, memórias e a própria identidade, em decorrência de eventos traumáticos), Tully encarna tudo aquilo que Marlo sente ter deixado para trás: entusiasmo, vitalidade, esperança, autoconfiança e beleza juvenil. Tully seria, assim, uma espécie de apoio mental e afetivo para uma Marlo amortecida pela maternidade vivida na chave individualista. Esse seria o efeito das exigências sociais contraditórias, dos julgamentos morais ácidos e dos problemas de comunicação para uma mulher de classe média que é mãe, esposa e profissional.

Esse estado liminar vivido pela personagem articula-se à configuração social específica na qual se insere a família de Marlo. A conjugalidade é um aspecto central 
na narrativa, e aqui podemos traçar um paralelo com o ideário do casal grávido estudado pela antropóloga Tania Salem (2007), no Rio de Janeiro dos anos 1980. Esse ideário representaria uma tentativa de mudança do padrão tradicional das relações conjugais e familiares, pautada pelos princípios da igualdade entre mulher e homem e do valor da "psicologicidade" (o desejo de se aprimorar como pessoa por meio do autoexame de consciência regular), visando à complementaridade simétrica, que engendra um jogo de reciprocidade e dependência.

Enquanto o casal grávido se delinearia durante a gestação e se reafirmaria por ocasião do parto, o pós-parto consistiria em um momento de crise, devido ao descompasso entre as expectativas em torno do casal igualitário e o que efetivamente acontece depois que a criança nasce. Um ideal semelhante parece estar presente no filme, pois o afastamento físico e emocional do marido da protagonista surge como fator decisivo no desenrolar da trama. O desequilíbrio na relação entre os cônjuges é acentuado, e a rede de apoio aparece como fator secundário. Inspiradas nas ideias de Emily Martin (2006), sugerimos que a imagem da sereia que ajuda Tully a sair do carro submerso representa uma percepção singular das contradições do modo de vida individualista, neoliberal, que são vividas por algumas mulheres no registro do adoecimento físico e mental. É como se, diante da percepção da impossibilidade de obter compreensão e apoio entre as pessoas próximas, restasse a ela apenas o recurso ao mundo da fantasia ou do inconsciente.

A abordagem antropológica do tema do puerpério em camadas médias urbanas convida à ampliação da reflexão sobre a forma cultural no interior da qual as mulheres estão vivendo a maternidade, a parentalidade, a conjugalidade, o cuidado (care) e a medicalização da vida - a exemplo da análise sociológica da depressão pós-parto produzida por Lorena Cronemberger (2019). E convida também à comparação com outras experiências de puerpério na sociedade brasileira, marcada por profundas desigualdades em termos de acesso a direitos sexuais e reprodutivos, como indicaram Laura Mattar e Simone Diniz (2012) e Flávia Biroli (2018).

Por seu estilo crítico e penetrante, Tully é um material importante a ser considerado nos debates sobre puerpério nos campos da Antropologia e da Saúde e pode igualmente ser inspirador para profissionais que atuam diretamente com mulheres que estão vivendo a experiência de maternar.

Recebido: 24/05/2019

Aprovado: 04/06/2019

Anuário Antropológico volume 44, n.2, 2019, pp.355-360 
Giovana Acacia Tempesta é doutora em Antropologia Social pela Universidade de Brasília e atualmente é pesquisadora-colaboradora plena vinculada ao PPGAS/UnB; realiza pesquisa de pós-doutorado sobre temas relacionados a parto e nascimento no Brasil, com ênfase na atuação de doulas. ORCID: 0000-0002-04691473. Contato: giovana.tempesta@gmail.com

Juliana Kitayama Cabral é graduanda em Antropologia na Universidade de Brasília; estuda sobre o puerpério com enfoque em mulheres brasileiras de camadas médias urbanas. ORCID: 0000-0002-6667-7490. Contato: jkitayamac@gmail.com

\section{Referências}

BIROLI, F. 2018. Gênero e desigualdades: limites da democracia no Brasil. São Paulo: Boitempo. CRONEMBERGER, L. 2019. Ser mãe é padecer no paraíso? O dispositivo da maternidade nas narrativas da depressão pós-parto. Dissertação de Mestrado, Universidade Federal da Paraíba, João Pessoa. MARTIN, E. 2005. A mulher no corpo: uma análise cultural da reprodução. Rio de Janeiro: Garamond. MATTAR, L.; DINIZ, C. S. G. 2012. Hierarquias reprodutivas: maternidade e desigualdades no exercício de direitos humanos pelas mulheres. Interface, v. 16, v. 40, p. 107-119.

SALEM, T. 2007. O casal grávido: disposições e dilemas da parceria igualitária. Rio de Janeiro: Editora FGV.

TURNER, V. 1974. O processo ritual: estrutura e antiestrutura. Rio de Janeiro: Vozes. 